\section{Virginia Gil Amate}

Profesora Titular de Literatura Hispanoamericana de la Universidad de Oviedo. Ha publicado las monografías Daniel Moyano: la búsqueda de una explicación (1993) y Sueños de unidad hispánica en el siglo XVIII. Un estudio de Tardes americanas de José Joaquín Granados y Gálvez (2011). Es editora de los volúmenes Teatro de la emigración asturiana en Cuba. Aproximación lingüística y literaria a la Biblioteca «Francisco de Paula Coronado» (1997) y Escritores sin Patria. La narrativa argentina de la segunda mitad del siglo XX (2006). Ha publicado diversos artículos sobre las letras virreinales, sobre el siglo XIX y sobre autores hispanoamericanos del siglo XX.

Susana Zanetti, en su excelente trabajo sobre la modernidad de la prosa de El lazarillo..., analiza las características distintivas del libro de Carrió dentro del marco sociopolítico colonial y las relación que establecen los hablantes en cuanto a la escritura y la lectura, precisamente al incidir en los modos de leer se refiere a las adulteraciones que la deliberada construcción de una literatura nacional ocasionó en el texto (Zanetti, 2002).

2

La inicial errata, quizá error por su insistencia ya que se repite en texto y nota, que deformaba el apellido del Fiscal de lo Civil de la Audiencia de Lima, Antonio Porlier, ha llegado a fijarse como un uso común en multitud de escritos referidos al Lazarillo... (Carilla, pp. 79 y 81 y nota 59 p. 80).

3

En realidad el nombre del que fuera Administrador de la Real Aduana en Arequipa era Juan Bautista Pando. Quizá la ausencia de la partícula unitiva y el hecho de que los apellidos no sean exclusivos de un único tronco familiar no haga tan seguro el parentesco entre el Administrador de Correos y el de la Contaduría.

Un lazarillo de capa y espada: las cuatro PPPP de Alonso Carrió de la Vandera

VIRGINIA GIL AMATE

\title{
UN LAZARILLO DE CAPA Y ESPADA: LAS CUATRO PPPP DE ALONSO CARRIÓ DE LA VANDERA
}

\author{
VIRGINIA GIL AMATE \\ Universidad de Oviedo \\ vigia@uniovi.es
}

\section{RESUMEN}

El presente trabajo se acerca al acertijo propuesto en las páginas de El lazarillo de ciegos caminantes atendiendo tanto al análisis del texto como a la información de la que se dispone sobre Alonso Carrió de la Vandera y la situación de la Real Renta de Correos en el virreinato del Perú. Plantea también los problemas que el autor y la obra pudieron tener al contravenir abiertamente las normas de impresión vigentes en el último cuarto del siglo XVIII.

Palabras clave: Alonso Carrió de la Vandera, El lazarillo de ciegos caminantes, censura, siglo XVIII.

\section{ABSTRACT}

This paper is about the riddle proposed in the pages of El lazarillo de ciegos caminantes. We analyze the text and the information that is available about Alonso Carrio de laVandera and the situation of the Real Renta of Correos in the Viceroyalty of Peru. It also suggets problems that the author and the work might have had to contravene current printing standards in the last quarter of the Eighteenth Century.

Keywords: Alonso Carrió de la Vandera, El lazarillo de ciegos caminantes, censure, Eighteenth century.

Emilio Carilla centró como enigma principal de El lazarillo de ciegos caminantes desentrañar el sentido de las cuatro PPPP, toda vez que a esas alturas de la historia ya no podía hablarse sin sonrojo de las deformaciones y arbitrariedades críticas que habían llegado a convertir en un «misterio» la verdadera autoría del libro'. Señaló, además, cuatro nombres, los de José Antonio de Pando, Administrador Principal de la Real Renta de Correos del virreinato del Perú; Felipe Porcell, Oficial Segundo de la misma Administración; Antonio Perlier², Fiscal de lo Civil de la Audiencia de Lima; y Juan Bautista de Pando 3 , Contador de la Real Aduana, con los que llenar de sentido, en el libro, el dicho popular, según indicaban las iniciales de sus apellidos. Carilla no tenía dudas en cuanto a los dos primeros, avalaba su presencia en ser públicos enemigos de Carrió y añadía los otros dos nombres, «si bien no con tanta firmeza» (1973, p. 79), basándose en que Juan Bautista debía ser, sin pruebas pero «sin duda»(1973, p. 79), pariente del Administrador, y en que Porlier, debido a su cargo, y según los datos recabados por Luis A. Ledesma Medina, «fue encargado, en 1772, de estudiar el Reglamento General de Correos elaborado por el administrador general, don José de Pando» (1973, p. 79). A esto añade que los cuatro vivían en Lima en la época y 
que sus nombres aparecen consignados en la Guia de forasteros de Lima, año 1779 de Cosme Bueno.

Como vemos, los argumentos para darles tal protagonismo en la obra al Contador de Aduana y al Fiscal de la Audiencia, no son muy sólidos ${ }^{4}$, sobre todo si, como certeramente indicó el propio investigador, la presencia de las PPPP no son un chiste más de los muchos que jalonan la amena lectura de El lazarillo..., sino un elemento esencial de la estructura narrativa que marca el sentido de la escritura de Carrió, el género del relato y las características de la edición del libro, cuyas claves habrían sido intencionadamente señaladas en el desarrollo de la obra. Por su parte, Antonio Lorente Medina, sin aventurarse a repetir los nombres con los que Carilla rellenaba, para el caso concreto de El lazarillo..., el dicho popular, consideraba que las cuatro PPPP escondían «un velado ataque a cuatro enemigos» (1985, p. XVI) del autor y se relacionaban directamente con el artificio creado por Carrió para la autoría, la licencia, el lugar de impresión, el año y la imprenta.

Una vez abierta la vía de investigación se han sucedido los estudios que proponían soluciones al acertijo. Todos ellos iban aportando conocimientos sobre la tradición cultural que podía estar manejando el autor (Fernández Insuela, 1990), sobre el marco virreinal en el que desarrolló su comisión (Hill, 2005), sobre sucesos concretos del ámbito político religioso que Carrió, con mayor o menor detalle, conoció (Klien-Samanez, 2002) e incluso trabajos que, más que sobre Carrió y su obra, ilustraban sobre las tendencias que adopta la crítica literaria contemporánea a la hora de analizar la literatura colonial (Stolley, 1992). No todos estas aportaciones se apoyaban en la información de la que se disponía desde los estudios de Walter B. L. Bose (1938 y 1941) y José Joaquín Real Díaz (1956 y 1959), algunas incluso consideraban desconectadas del texto la aparición de las cuatro PPPP y, otras, llegaban (o partían) de conclusiones tan peregrinas que desfiguraban el sentido de la escritura de Carrió y de los rigurosos estudios que hasta el momento se habían hecho sobre la obra y el autor. El resultado final abocaba al cambio de la orientación del uso de las PPPP en el libro, cayendo de paso la constante ironía de Carrió y el ataque personal y directo de su escritura, para pasar de lo concreto, de lo que en la narración se expresa, a un plano más difuso, a aquello que se intuye que hay en él. Paradójicamente para este cambio de la filiación de signo histórico y personal dada por Carilla, se utilizaba no aquello que las PPPP apenas velaban en la obra sino la solemne mofa final, puesta en boca del Visitador en forma de parábola, al plantear una «burla chistosa que hizo un gatemalteco gachupín a ciertos chapetones limeños» ${ }^{5}$ (p. 224), donde las PPPP serían o bien «Pila, Puente, Pan y Peines» o bien «Pedro, Pardo, Paulino y Perulero» (p. 227, corregimos la errata que figura en el segundo nombre).

Mi intención es retomar la senda abierta por los estudios literarios de Real Díaz, Marcel Bataillon, Emilio Carilla y Antonio Lorente Medina para buscar en el libro y en las circunstancias del autor sus iniciales claves de lectura y la explicación de sus enigmas, puesto que actualmente contamos con más información sobre Carrió, José Antonio de Pando y la situación de la Administración de Correos en el virreinato del Perú, de la que ellos pudieron disponer. Ahora no resultan tan discretas, como apreció Bataillon (1960), las múltiples andanadas que Carrió lanza hacia Pando y sus dependientes en la Administración Principal de Lima, si bien es cierto que la mayoría de ellas están construidas, según señaló Lorente Medina, mediante la alusión indirecta (1985, p. XV) y sazonadas con el grueso humor, a veces con el abierto sarcasmo, que caracteriza la prosa de El Lazarillo...

Empecemos entonces por el principio, por las alusiones a las cuatro PPPP que figuran en el prólogo, en el capítulo XI de las ediciones modernas, y en el apéndice que cierra la obra. La primera chanza ya contiene elementos fundamentales de la disputa que mantenían Carrió y Pando. Este había publicado, en septiembre de 1772, previa presentación al Virrey Amat, pero sin la aprobación del Superintendente General de Correos ni la preceptiva sanción Real, el Reglamento General y Metódico para el funcionamiento de correos en el virreinato. Establecía en él, entre otras cosas, las rutas, las distancias y el nombramiento de los conductores que, a caballo, cubrirían las carreras de Cuzco, Piura y Arequipa (Sitjá Prats, 2013 pp. 151-154). Las postas señaladas entre Cuzco y
Carta certificada 1785. Fuente Sitjá Prats

Antonio Insuela, además de corregir el error en el apellido del Marqués de Bajamar, detectó esta falla en la hipótesis de Carilla (1990, p. 848).

5

Todas las citas de este trabajo están basadas en la edición de Lorente Medina (1985).

Un lazarillo de capa y espada: las cuatro PPPP de Alonso Carrió de la Vandera

VIRGINIA GIL AMATE 
En la carta, fechada el 12 de enero de 1771, Grimaldi le comunicaba a Pando el nombramiento de Alonso Carrió como Visitador de la ruta de Buenos Aires a Lima, le recomendaba, además, que se apoyara en su experiencia "por su dilatado conocimiento del Pays y caracter de sus Habitantes, y por la práctica que tiene en asumptos de Comercio» una vez que el Visitador llegar a Lima $y$, finalmente, le indicaba que "se le proporcione destino, que se acomode con su modo de pensar, prevengo a $\mathrm{Vm}$. que en el caso de ser preciso que el ramo de Correos y Encomiendas de este Reino haya de tener en esa Capital Interventor, o Tesorero, se le prefiera a cualquiera otro que pretenda un tal destino, pues es el unico que en el citado ramo le puede estar bien» (Sitjá Prats, pp.180-181).

7

En la carta que Pando envió a los Administradores Generales el 24 de enero de 1773, anotaba: «En quanto al nombramiento de oficiales para el Servicio, y manejo de esta Administración Grâl de Correos del Reyno tube muy poco que hacer en preferir a Don Jph Albarez de Naba, para la plaza de Oficial Mayor, o primero de ella, con el sueldo provisional de novecientos pesos annuales, pues al paso que este sugeto se ha distinguido con el mayor empeño y deseo del acierto en todos los asuntos de la mayor entidad y confianza que se ofrecieron en el servicio de la Renta, y que por mi dilatada enfermedad en Sta. Feè, fue el principal agente de ellos, aviendole Comisionado últimamente desde la ciudad de Piura, para que viniese delante y solicitase casa en que establecer la oficina, cuyo encargo desempeño con el mayhor acierto y conducta, le he considerado muy necesario a mi lado en esta Administracion Prâl para tener en quien descansar de las considerables fatigas $y$ cuidados que ocasiona la nueva planta y arreglo de Correos en este Virreynato» (Sitiá Prats, p. 128)

Real Díaz apunta que Juan Antonio de Pando "se dejó gobernar por una "camarilla» en la que

Un lazarillo de capa y espada: las cuatro PPPP de Alonso Carrió de la Vandera

VIRGINIA GIL AMATE

Lima fueron duramente criticadas por Carrió en los sucesivos informes que enviaba a Madrid, indicando un camino alternativo hasta Huancavelica por el que se recorría una distancia de 148 leguas, en lugar de las 184 marcada en las disposiciones de Pando. A esto añadía el Comisionado que las rutas de esa parte del Perú debían realizarse en mula porque la orografía hacía inútil la velocidad de los caballos. El Reglamento multiplicaba los correos entre Lima y Cuzco y entre Cuzco y Potosí, pasando de siete anuales a veinticuatro, medida también rebatida por Carrió al considerarla inadecuada, exagerada y cara. Pando había, además, nombrado a José Álvarez de Nava, con el que realizó el largo y accidentado viaje desde Veracruz a Lima entre febrero de 1769 y mayo de 1772, Oficial Mayor o Primero de la Administración principal, añadiendo, en carta a los Administradores Generales, que «podría este Dependiente como tal oficial primero, ejercer las vezes de Interventor, a fin de no agravar a la Renta con duplicados sueldos de empleados» (24/I/1773, Sitjá Prats, p. 128). Esta maniobra bloqueaba las posibilidades de Alonso Carrió para ocupar el puesto de Interventor que figuraba en las instrucciones dadas por el Marqués de Grimaldi a Pando en 17716. José Álvarez de Nava, no es difícil pensar que «Pepe» para sus amigos, fue persona de la máxima confianza de Pando a lo largo de todo su mandato ${ }^{7}$ y alguien que, como poco, sacaba de quicio a don Alonso $^{8}$, por eso debería, con más fundamentos que otros, formar parte de las famosas, por obra de Carrió, PPPP de Lima.

Teniendo en cuenta estos datos, la primera alusión a las PPPP ya es un dardazo poco confuso a la cúpula del poder en la Administración de Correos del virreinato, construido mediante la inserción de referencias a dichos y personajes que formaban parte de la cultura popular peruana, así Juan de la Cova, símbolo del fraude de las altas esferas y también de la venganza cómico-burlesca del gentío, o la exclusiva aceituna -tan común que fue recogida por Ricado Palma, al igual que la de Juan de la Coba, en sus Tradiciones-, con las que «el

ejerció el predominio don José Álvarez de Nava» (1956, p. 392). En la correspondencia de Carrió con los Directores Generales suele referirse en plural a aquellos que dirigen los Correos en el Perú, son los «mozos» que no se avie- nen con su «modo de pensar» (Real Díaz, 1956, p. 393), y alude en concreto a Nava al recibir noticias, ya publicado El lazarillo..., de los rumores que pueden estar corriendo en España sobre el carácter satírico de la obra: «aunque recelo

cojo Nava» ${ }^{9}$, muy ahorrativo el personaje sobre todo si quería matar al animal, podía, según Concolorcorvo, alimentar una mula. No perdamos de vista que en la disposiciones de Pando el bajo salario asignado a los conductores de correos se compensaba con la autorización para llevar mercancías, exentas de impuestos, con las que comerciar. Medida esta inadmisible para Carrió porque, a más de no dignificar, por medio de un pago justo, la dura y necesaria labor de los conductores, propiciaba el retraso de los correos, el incremento desordenado de las cargas, la atención al negocio particular sobre los intereses generales de los usuarios de Correos y el malestar y la protesta de los comerciantes.

También es significativa la localización narrativa del fragmento porque las PPPP aparecen, en esta primera ocasión, inmediatamente antes de poner en conocimiento de los lectores que sólo de Buenos Aires a Jujuy se hacen las rutas a caballo por ser terreno llano, «todo lo demás de este gran virreinato se camina en mulas» (p. 7) y entrecortando una disquisición de Concolorcorvo sobre las postas en las que, entre otras cosas, destaca su utilidad «al Estado para comunicar y recibir con presteza las noticias importantes, de que se pueden servir también los particulares para sus negocios, precediendo las licencias necesarias prevenidas en las Cédulas Reales y Ordenanza de Correos para la precaución de que no caminen por la posta delincuentes, sino personas libres de toda sospecha» (p. 6), Reales Ordenanzas que se había saltado Pando en muchos puntos sobre todo con la difusión del Reglamento y que, por supuesto, aunque no parece percatarse de ello, también iba a sortear Carrió al publicar, sin licencia, el libro en el que estaba incluyendo estas denuncias. Dice así este primer aviso a los lectores:

En este dilatado reino hay verdaderamente hombres curiosos, porque jamás hemos visto que un cuzqueño toma postas para pasar a Lima con solo el fin de ver las cuatro prodigiosas P.P.P.P., ni a comunicar ni

mucho sean chismes de Nava» (Carta de Alonso Carrió de la Vandera a los Directores Generales, $20 / / \mathrm{V} / 1777$, Real Díaz, 1956, p. 415). A Nava, en el Manifiesto, lo denominaba «el candidato» (Sitjá Prats, p. 192).
Carilla, sin embargo, señala que «no hay ningún motivo para sospechar que Carrió desliza aquí una ironía hacia José Álvarez de Nava, miembro de la camarilla de su enemigo José Antonio de Pando» (1973, nota 14, p. 104). 
a oír las gracias del insigne Juan de la Cova, como asimismo ningún limeño pasar a Cuzco sólo por ver el Rodadero y fortaleza del Inca, y comunicar al Cojo Nava, hombre en la realidad raro, porque, según mis paisanos, mantiene una mula con una aceituna (p. 7).

En el prólogo Concolorcorvo ha recorrido no sólo todos los puntos concretos del enfrentamiento profesional entre Carrió y Pando, sino que también se ha burlado del solemne establecimiento de tratados para un asunto, las postas, que en la parte geográfica «son de institución natural» (p. 5) y en la técnica más bien debería seguirse lo que «sucede en todo el mundo» (p. 8 y 12), frase esta muy repetida por el amanuense cada vez que quiere referirse de modo indirecto a las ocurrencias personalistas que hagan del virreinato del Perú un sitio aparte de las medidas generales para el buen funcionamiento de los correos. Y por si fuera poco, no deja de referirse en varios momentos a los empachos que la «juventud» (p. 9) padece por atracarse de «fiambres», para terminar enfermos de terciarias «con particularidad en las tierras calientes» (p. 9) a los que se suman los que llegan «a esta capital por la costa de Arequipa» en pésimo estado, a diferencia de los que llegan por zonas más secas y «son más económicos porque se aplican más al método serrano» (p. 13), las entradas en Lima de Pando y sus dependientes (incluida la de Porcell), la enfermedad que hizo tan penoso y largo el traslado del Administrador Principal a Lima, quedan retratadas en este prólogo y volverá a reiterarse en el último apéndice, con el estilo propio del Visitador dado a las jocosidades, según anuncia Concolorcorvo.

La siguiente irrupción de las PPPP se produce nada más empezar la segunda parte, aquella que, narrativamente, comienza en Potosí y termina en Huancavelica. Es la parte más técnica en materia de correos y la más informativa sobre las postas que el Visitador había establecido entre Cuzco y Lima, contrarias a las rutas indicadas en el Reglamento de Pando. Recorría la escritura los territorios en los que Carrió había introducido más novedades, puesto que, hasta Jujuy, las postas, las rutas y el funcionamiento del correo ya había sido organizado, y del mejor modo a criterio de Carrió, por Domingo Basavilbaso. Esa primera sección de su visita, narrada en la primera parte, sólo necesitaba algunos ajustes y la comunicación de zonas más ol- vidadas, como los territorios del noroeste argentino y las vías a Santiago de Chile. Por eso, por no ser tan necesaria la exposición de su criterio y labor, la información relativa al correo se combina con amenas descripciones del espacio natural, de la población y de las costumbres, unidas al anecdotario que jalona el viaje, funcionando en ella a la perfección el burlón artificio literario de desdoblar la voz del autor entre el Visitador y su amanuense.

La segunda parte, sin embargo, mostraba la completa disensión entre Carrió y Pando y los puntos que, junto a la decisión del Comisionado, consensuada con Basavilbaso, de hacer depender de la Administración de Buenos Aires las estafetas de todos los territorios del Tucumán, de los situados al este de la cordillera y de la provincia del Paraguay, desvinculándolos de la de Lima, motivaron el enfrentamiento entre los protagonistas de este enredo extraliterario. Siendo, como digo, la más técnica es la más entrecortada por asuntos que parecen alejarse de la diatriba central del libro. En ellas Concolorcorvo y don Alonso pasan revista a asuntos de la primera actualidad política del momento, así la revisión de la conquista, el grado de evangelización de los indígenas, la falta de preparación del clero, las diatribas sobre la Compañía de Jesús, la castellanización de los territorios americanos, la lamentable organización local del territorio o las urgentes reformas en materia económica necesarias para el progreso de los virreinatos. Con la excepción de la castellanización, cada uno de esos temas (más aún si van todos juntos) incidía en asuntos que no estaba en la potestad de los particulares tratar alegremente sin previa revisión y permiso del Consejo de Castilla. En medio de ese alarde, dilatándolos, dosificándolos, introduciéndolos aquí y allá, continúan los ataques a Pando y sus dependientes y da igual que estén hablando de la ruta o de la conquista. Por ejemplo, al encaminarse la conversación hacia la dificultad que los conquistadores tuvieron para someter el territorio chileno, Concolorcorvo terminará apuntando una reflexión del Visitador sobre los peligros de una mala dirección si esta está en manos de inexpertos, de «bisoños»:
Fuente Sitjá Prats

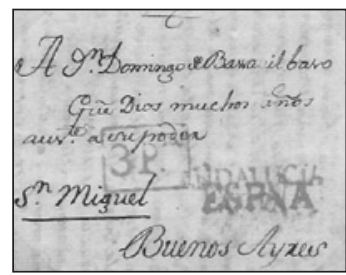

Un lazarillo de capa y espada: las cuatro PPPP de Alonso Carrió de la Vandera

VIRGINIA GIL AMATE 


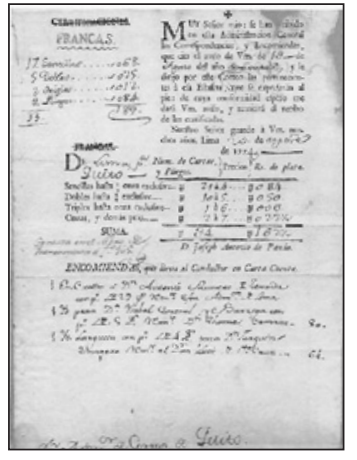

Guía de las tarifas empleadas de Quito a Lima. 1774. Fuente. Sitjá Prats

Un lazarillo de capa y espada: las cuatro PPPP de Alonso Carrió de la Vandera

VIRGINIA GIL AMATE
Estas reflexiones prueban que un numeroso ejército, tumultuariamente dirigido, de doscientos mil hombres, aunque sean soldados veteranos, si los oficiales generales son bisoños, puede ser derrotado y puesto en fuga por treinta mil soldados bien disciplinados, al cargo de caudillos sabios y valerosos (p. 171).

Todas las alusiones dispersas están presididas por la segunda aparición de las cuatro PPPP. El zarpazo se coloca al inicio de la descripción de Potosí, una vez que se ha nombrado a Pedro de la Revilla, el Administrador de correos de la villa, y esto le ha dado pie a Concolorcorvo para referirse a los rumores que «por malicia» (p. 111), según el Visitador, se extendieron en Potosí sobre las anteriores y viles ocupaciones que había tenido en España. Agrega don Alonso otro caso relacionado con infundios, el protagonizado por Pedro Sánchez Villalva en Popayán. Este, si bien estuvo motivado por la «sencillez» (p. 111) del vulgo, tuvo peor resolución al terminar el difamado ante el tribunal de la Inquisición. Los chismes que alteran identidades se mezclan en la narración con la referencia a las arbitrariedades etimológicas, al relatar el Visitador el baile de letras ocasionado en Arequipa con el apellido de José Gorosabel que quedaba transmutado, por «cierto bufón» (p. 111), en Zorobabel y su portador en descendiente de judíos. Alude entonces a las cuatro PPPP:

Lo cierto es, señor Concolorcorvo, que de cien hombres apenas se hallará uno que no sea titiritero, y así ríase $\mathrm{Vm}$. de los potosinos y popayanes con los dos Pedros y celebre cuatro P.P.P.P. tan memorables como las de Lima (p. 111).

y el comentario parece incidir en la esencia del popular juego con las iniciales siendo esta, en palabras de Herrera Navarro, «que en cada lugar, en cada sitio, en cada casa, las cuatro PPPP significan una cosa distinta, y en la suya, en el ámbito de los Correos - La Robada- coincidirían con los funcionarios responsables del estado en que se encontra$\mathrm{ba}$, es decir, con sus enemigos, empezando por Pando» (Herrera Navarro, p. 509). Así, cualquier lector de la obra podía entretenerse, tanto el amplio abanico de lectores al que se abría El lazarillo... para su autor ficticio -los «empolvados caminantes» $\mathrm{y}$ «los poltrones de ejercicio sedentario» (p. 5)-, como los concretos lectores, los «Administradores Mayores de la Renta, desde Montevideo a Cartagena con sus travesías» (Real Díaz, 1956, p. 410), a los que distingue Carrió como destinatarios principales de su obra en carta de 24 de abril de 1776 enviada a los Directores Generales. Esos sabrían perfectamente con qué nombres llenaba su intermitente broma el antiguo Visitador, sobre todo si, a continuación del acertijo, Concolorcorvo pasaba a hablar de la opulencia potosina que contrasta con las dificultades del trasporte de mercancías por el terreno yerto que la rodea, por la ausencia de postas, por la mala distribución de los recursos públicos y la explotación a la que estaban sometidos los arrieros y los indios de la zona. El Visitador había tomado cartas en el asunto, negociando con los panaderos de Potosí, «que comúnmente tienen mulas gordas y descansadas en sus corrales", para que proporcionaran mulas «a precio regulado» eximiéndoles a cambio «de una contribución que hacían anualmente para una fiesta profana» (p. 112), pero intervino la autoridad contraviniendo sus medidas y así «quedaron frustradas sus diligencias porque se opuso cierto ministro de espíritu negativo» (p. 112).

En la rememoración del viaje que efectúa Carrió en las páginas de El lazarillo... Potosí funciona como el lugar donde comienzan los problemas del Visitador que, según Concolorcorvo, «no le abatieron el ánimo» (p. 112), es más, siguió organizando los asuntos relativos al correo y, una vez consideró finalizada su tarea, «resolvió pasar a Chuquisaca» para continuar con su misión, no obstante «desconfiar del buen éxito de su visita» (p. 112). Es la época en la que Pando, acompañado de Nava y Gabriel García de la Plaza, se personó en Lima. Ocho meses después de su llegada, el 24 de enero de 1773, en carta enviada a los Directores Generales para informarles de las medidas y los nombramientos efectuados, se refería a sus dependientes en estos términos:

A mi llegada a esta Capital de Lima con los dos únicos y principales dependientes don Joseph Albarez Nava, y don Gabriel Garcia de la Plaza, que siguieron conmigo desde la Habana en calidad de oficiales de visita, por todo el virreynato de Stan Feé, desempeñando con particular amor y celo del Rl Servici, quantos asumtos se ofrecieron de la mayor atención en el establecimiento y arreglo de la Renta en aquellas partes, y que por su distinguido merito y arreglada conducta, me parecio indispensable deber conserbarlos en mi compañía, para extablecer esta Admón. Gral de Correos del Reyno. (Sitjá Prats, p. 128) 
Pando nombraba a Nava, como dijimos, Oficial Mayor o Primero, dejaba el cargo de Oficial Segundo para Felipe Porcell «a quien Vss. se sirvieron librar Titulo con fha de 3 de Diê del año pasado de 1770 para que sirviese de operario a mi lado en esta Admón. Grâl de Correos, con el sueldo de ochocientos pesos, que el Excmô Super Ynte. Grâ Marques de Grimaldi, le había señalado para desde el día en que hiciese constar su embarque en La Coruña, a este destino» (Sitjá Prats, 2013, p. 128), señalando a las claras cual era el cometido inicial de Porcell puesto que este ya había tenido un encontronazo con Carrió, con el que había viajado en el Tucumán de La Coruña a Montevideo, cuando el Comisionado le indicó que debía acompañarlo en su visita y ayudarlo en el establecimiento de las postas de Santiago de Chile y Porcell, entendiendo que sus órdenes no lo obligaban a semejante viaje, se dirigió directamente a Lima ${ }^{10}$.

Gabriel García de la Plaza, que también ostenta en su apellido una indiscutible $P$, fue nombrado Oficial Tercero «haciendo a este Dependiente la injusticia, de posponerle a dho Porcell, en la regulacion, pero reflexionando, a que esta no puede serbir de ningun obstaculo para conocer el merito de los sugetos» (Sitjá Prats, 2013, p. 129). Quiere esto decir que los Directores Generales sabrían los nombres de los funcionarios principales de la Administración de Lima a principios de 1773. Todos ellos, Pando, (Pepe) Nava, Porcell y Plaza bien podrían ser las cuatro PPPP que cualquier administrador de las estafetas de correos del virreinato del Perú podrían previamente conocer antes de que les llegara, al menos esa era la intención de Carrió, uno de los 500 ejemplares de El lazarillo... que el Comisionado imprimió por su cuenta hacia 1775 o 1776, época en la que Pando «le había relegado a tener una mesa fuera de la oficina principal» (Sitjá Prats, 2013, p. 196).

Aún antes de publicar el Reglamento, Pando había enviado, el 18 de agosto de 1772, y un día después a Carrió, una carta a todos los Administradores de la carrera de Cuzco con la que empiezan, si no las disensiones, sí la batalla abierta entre el Administrador Principal de Lima y el Comisionado para establecer las postas entre Buenos Aires y Lima ${ }^{11}$. La circular de Pando contradecía las instrucciones dadas por Carrió relativas al franqueo de las cartas. Este, siguiendo las nuevas ordenanzas de Correos ya aplicadas en España, indicaba que el coste de los portes de cartas y encomiendas podían pagarse, si así lo decidía el remitente, en destino, evitando el posible fraude a los usuarios del servicio de Correos, de ahí que las estafetas por las que había ido pasando Carrió hubieran abierto una rejilla al público para que pudieran depositarse las cartas no francas. Pando, por el contrario, había mantenido el sistema que regía en el Perú desde la época en que los condes de Castillejo se encargaban del correo, obligando al pago en el momento del envío. La furibunda respuesta de Carrió a esa misiva halla su eco no sólo en la carta que le envió a Pando el 14 de octubre de 1772, sino en los asuntos que irá tocando, a partir de su paso por Potosí, en El lazarillo.... El mensaje personal al Administrador de Lima avisaba de lo que le aguardaría en el futuro inmediato:

Muy Sr. Mío: La circular que Vm escrivió con fha 18 de Agosto a todos los Administradores de la Carrera General y Travesías, y la que me dirigió a mi con fha del 19 del propio, una y otra injuriosa a mi acreditado proceder no merecian mas respuesta que una estocada por cada linea; pero como esta prohivido por Leyes divinas y humanas este genero de satisfacciones, y estan encargados los Juezes del castigo de semejantes atentados, protexto ocurrir adonde mas me convenga, para el desagravio de la injuria de $\mathrm{Vm}$ me hace (Sitjá Prats, 2013, p. 172).

Los asuntos tratados en la segunda parte de la obra comprenden, cuando el Visitador y su amanuense están en La Plata (Charcas), es decir en el apartado siguiente al de Potosí, una refutación del Reglamento de Pando hecha a base de describir las medidas tomadas, apoyadas en el conocimiento práctico. Por supuesto el artefacto literario creado es de tal calidad y de tal originalidad que Pando queda retratado como un perfecto incompetente, lo fuera o no. Creo que es esa continua mengua de la talla del Administrador General y sus dependientes lo que persigue El lazarillo..., no tanto el apuntalamiento (y menos a consta de Concolorcorvo) de la figura del Visitador que para la época en la que se proyecta y redacta la obra, entre 1773 y 1775, no creía necesitar, ni ante las autoridades virreinales ni ante las centrales, Carrió.

Se inaugura ese capítulo XII con una sátira «mal fundada» (p. 117), según Concolorcorvo, alusiva al respeto meramente protocolario que la plebe tiene hacia los superiores, al no haber sido ganado este a fuerza de buen hacer,
10

Sitjá Prats transcribe íntegra la carta que Carrió le envió a Porcell el 25 de junio de 1771 conminándolo a cumplir las órdenes que le había dado para que realizara la visita de la ruta entre Buenos Aries y Santiago de Chile, instrucción que Porcell desoyó (pp. 187-188).

11

Con el estilo ajeno a componendas que manejaba en su correspondencia, Alonso Carrió informaba a los Directores Generales, poco después de recibir la circular con la que Pando anulaba sus disposiciones, de la disputa que ya no acabará hasta 1777: «Muy SSres mios: Ya se acabó de declarar la guerra que presumi haria Pando a mi Comisión, ê insinue a Vss. en mi carta de 19 de Agosto, con atropellamiento, no solo de mi persona, sino de las terminantes ordenes de Vss.» (16/X/1772, Sitjá Prats, p. 183).

Un lazarillo de capa y espada: las cuatro PPPP de Alonso Carrió de la Vandera

VIRGINIA GIL AMATE 


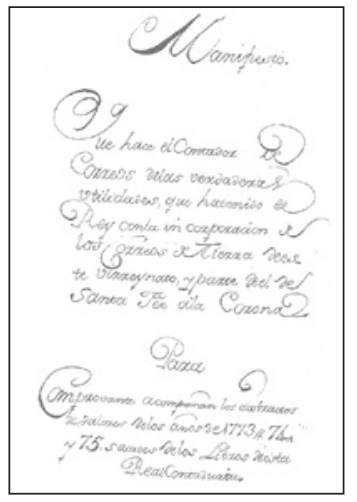

Portada del Manifiesto de Alonso Carrió de la Vandera, 1777. Fuente Sitjá Prats

12

Así lo advierte también Carla Mariela Almanza Gálvez (2005, p. 74) pero sus conclusiones, rebajar a través de este recurso ficcional la voz del autor para dar importancia al texto $(2005$ p. 75) y trazar una deliberada «degradación de la imagen del escritor» (2005, p. 77) para el mismo fin, no coincide con las de este trabajo. Susana Zanetti planteó de otra manera la relación establecida entre los hablantes de Carrió, en ella El lazarillo mostraba la construcción ideológica de un pacto colonial basado en la integración por asimilación de lo indígena a lo hispánico. En su base había, indudablemente, un sometimiento pero también un diálogo que configuraba una imagen del mundo americano diferente de la de España (Zanetti, 2002).

Un lazarillo de capa y espada: las cuatro PPPP de Alonso Carrió de la Vandera

VIRGINIA GIL AMATE al contrario, conociendo bien los de abajo las triquiñuelas de los de arriba, por lo que, a veces, la sumisión rezuma malestar:

Es natural la seriedad en los ministros públicos, y también el respeto, aunque violento, en algunos súbditos. En todos hay algo de artificio, con la diferencia de que los señores ministros piensan que aquel rendimiento les es debido, y el público, como ve que es artificial, vitupera lo que hace por su conveniencia y particulares intereses, y exagera la vanidad y soberbia de unos hombres que no pensaron en semejantes rendimientos (p. 117).

Por supuesto, el «humilde» Concolorcorvo, tantas veces alter ego de Carrió en las páginas de El lazarillo... ${ }^{12}$, aunque no siempre haya saltado a la vista de los críticos dolidos con el «racismo» y la mentalidad «colonialista» del autor, lanza la andanada y luego la difumina aduciendo que tal situación, como bien sabrían los lectores del último cuarto del siglo XVIII y los administradores de cualquier estafeta de correos del Perú, «pasaba antaño, pero hogaño reconocemos que estos señores ministros, conservando su seriedad, son muy moderados y atentos en la calle, y en sus casas muy políticos y condescendientes en todo aquello que no se opone a las buenas costumbres y urbanidad» (p. 117). La matización, el equívoco servilismo de Concolorcorvo, no diluye el contenido de la ácida ironía, más bien lo incrementa al construir un relato que multiplica las posibilidades de interpretación partiendo de dos básicas: aquella que terminará en carcajada, la de los que comparten la visión crítica de Carrió y saben que lo de antaño sigue pasando hogaño, estén o no enterados de los asuntos concretos a los que alude; y otra que acarreará el disgusto o la ira de los que se reconocerán en el blanco de la broma. A partir de esos dos niveles existen otras posibilidades creadas por la maestría literaria del Comisionado puesto que el personaje, en algunos pasajes, representa arquetípica y humorísticamente a determinados sectores de indios y mestizos principales, de ahí que por momentos los lectores de la época pudieran reconocer ecos que dibujan el viaje concreto del Visitador y su amanuense por la geografía del Perú tanto como por la historia coetánea. Así funciona la prosa de Carrió: escribe un libro de ataque personal bajo la forma de la narrativa de viajes, en el que lo literario, al menos la originalidad literaria del texto, no estaría tanto en los recursos ficcionales utilizados, puesto que estos no eran del todo novedosos, sino en el efecto de lectura, en las múltiples posibilidades simbólicas e interpretativas de El lazarillo...

Predispuestos los lectores con la broma inicial, comienza el ataque. Concolorcorvo apunta lo que ve y, ante el descontrol de la oficina de La Plata, lo que observa es al Visitador «reflexionando» sobre los prejuicios que se le hacen a la Real Hacienda por no haberse calibrado bien, a la hora del arrendamiento de la estafeta, ni las distancias ni el monto de los portes, por lo que «era preciso averiguar los legítimos valores para formar un reglamento sólido» (p. 120) y, por si a alguien le había parecido oscura la referencia, remacha:

Y concluida esta diligencia [el nombramiento de Juan Antonio Ruiz de Tagle para organizar de forma cabal la oficina] pidió bagajes el visitador para continuar su comisión; pero antes de salir me parece justo prevenir al público, y aun a los señores directores generales de la renta de correos, la diferencia que hay de los señores ministros de carácter y letras a los demás jueces inferiores, sin letras ni ápice de reflexión, por lo general (p. 120).

A continuación irá referida toda la batería de órdenes y contraórdenes que se cruzaron Pando y Carrió entre 1772 y 1773. Así la que atañía a la hora de salida de los correos, fijada por Pando a las 12 de la noche y por Carrió a las 12 del medio día (p. 121); las cartas francas (p. 126); y las rutas de la carrera de Lima a Cuzco propuestas por el Visitador que se irán anotando y justificando en esta segunda parte de El lazarillo.... El texto procede diáfanamente exponiendo la versión de Carrió sobre los hechos y sin aludir directamente a la polémica. Por ejemplo, si el 20 de noviembre de 1773, Pando había contestado a las durísimas palabras de los Directores Generales sobre los inicios de su gestión, alegando la total falta de información suministrada por el Comisionado -«Don Alonso aseguró a Vss. que desde Buenos Aires avia dado noticia de quanto iba actuando en su visita, y avía ejecutado asta Potosí. Pero yo les aseguro que tan lejos estuvo es escrivirme, que solo podrá justificarlo con la única en que me dio cuenta de su arribo à Montevideo, y las dos que dirigió desde Buenos Aires, al Administrador Ynterino, antes de mi regreso a esta Capital» (Sitjá Prats, p. 183), «Visto que Don Alonso 
permanecía en su silencio, la lentitud con que proseguía en su visita, y que quanto notició al Superior Govierno relativo a los oficios, y extablecimientos de Correos desde Buenos Aires, à Potosí, estaba reducido al Plan...» (Sitjá Prats, p. 184)-, Carrió le enmendaba la plana en las páginas de su relato:

Desde El Cuzco había consultado el visitador al superior gobierno la ruta de los correos por Viña, dirigiendo un derrotero que le habían propuesto varios hombres prácticos, de que se dio traslado al Administrador General de Correos, quien puso algunas dificultades, dictadas de sujetos sin formal conocimiento (p. 195).

Si el Administrador Principal había señalado en el Reglamento una ruta entre Lima y Huancavelica diferente a la planteada por Carrió en sus informes, Concolorcorvo se encargará de calificar la decisión emanada de la Oficina Principal:

De Chilca a Lurín hay siete leguas, con algunos arenales poco molestos. Aquí sobran las mulas porque hay abundancia de pastos todo el año, y por eso hay tanto trajín a Lima, que a todas horas se encuentra(n) en la tablada nombrada la Mamacona, que es el único arenal algo molesto y ponderado de cierto informante bisoño. De este pueblo a Lima hay seis leguas, aunque los correos del rey han pagado cinco. Hay hombres que no saben otra cosa que contradecir y oponerse a todas la ideas que no son propias [...] los más de los harrieros gruesos que descienden del Cuzco y suben con carga doble, vienen y van por estos arenales, que pondera insuperables el rígido censor, que no conozco ni quiero conocer (p. 202).

Para terminar abochornando a Pando puesto que en la ruta de Piura y Arequipa, que el mismo Administrador Principal había establecido sobre el terreno, no alteró el rumbo de los puntos principales de ninguna carrera por encontrarse con arenales de grandes dimensiones y «mayores distancias» (p. 202) que los de Cuzco.

Sigue el repaso al Reglamento con el innecesario gravamen a la Real Hacienda que supondría, según Pando, establecer casas de postas en la ruta indicada por Carrió. Es este, para Concolorcorvo, «un reparo pueril o muy malicioso, porque la renta jamás ha tenido ni tiene casa alguna, y mucho menos la necesita en esta ruta» (p. 202). Como Pando había establecido que la carrera principal pasara por Jauja, Concolorcorvo replica que «El otro reparo que se puso de que carecían de correspondencia los vecinos del valle de Jauja y provincia de Tarna, es un trampantojo para espantar ignorantes. Lo primero, porque saliendo diariamente harrieros y pasajeros de estas dos provincias para Lima, dirigen con ellos los vecinos su correspondencia» (p. 202). Para concluir la demolición pública de las ideas de Pando y sus asesores desvinculando las rutas necesarias de un servicio público de aquellas que pueden querer seguir, en sus particulares viajes, los miembros de las élites:

Para dar fin a este itinerario se previene que no es regla infalible para graduar de mejor ruta, la que siguen las personas distinguidas y de conveniencias, porque todos estos señores eligen las dos mejores estaciones del año. Para los correos, que caminan por precisión en días determinados, se debe elegir una ruta que no tenga impedimento grave en ninguna estación (p. 203).

Es en el chiste con el que «cierra» su itinerario por el territorio del Perú y por los puntos de la contienda en el seno de Correos, cuando, de forma indirecta, retrata a los que quieren desafiar el conocimiento adquirido por experiencia y a los que tratan de reírse de la gente común atrincherados en la idea de su superioridad cultural foránea. Pone en escena a un inglés presuntuoso retando, a golpe de dinero, a varios comerciantes del Río de la Plata que haría llegar una carta de Buenos Aires a Córdoba en cuarenta y ocho horas, ruta que estaba fijada en 150 leguas, «aunque el visitador sólo graduó ciento cuarenta y seis» (p. 204). Siendo la apuesta de cuatro mil pesos y sin que los comerciantes supieran cómo iba a arreglárselas el inglés para cruzar el territorio en $\tan$ breve tiempo, llaman «al corredor cordobés, que era el más acreditado en aquella carrera» (p. 204). A este, de modales rústicos, no se le escapaba que la distancia podía recorrerse con postas de refresco, así que «echándole dos (z)ahumerios en las barbas» (p. 204) aceptó el desafío rebajando el envite a «veinte pesillos (así se explican ellos para manifestar una corta cantidad)» (p. 204), porque si bien los lugareños no tenían ni los caudales, ni el refinado estilo del bravucón, no les faltaba ni inteligencia ni conocimiento. «Oiga el inglesillo», dice para terminar el tucumán, "¿le parece que aquí, aunque semos unos probes, no le entendemos sus trafacías?» (p.

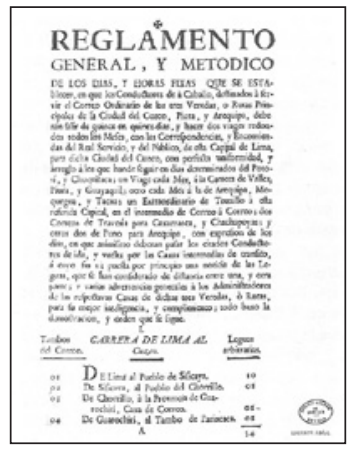

Reglamento de Jose Antonio de Pando, 1772. Fuente Sitjá Prats
Un lazarillo de capa y espada: las
cuatro PPPP de Alonso Carrió de la Vandera

VIRGINIA GIL AMATE 


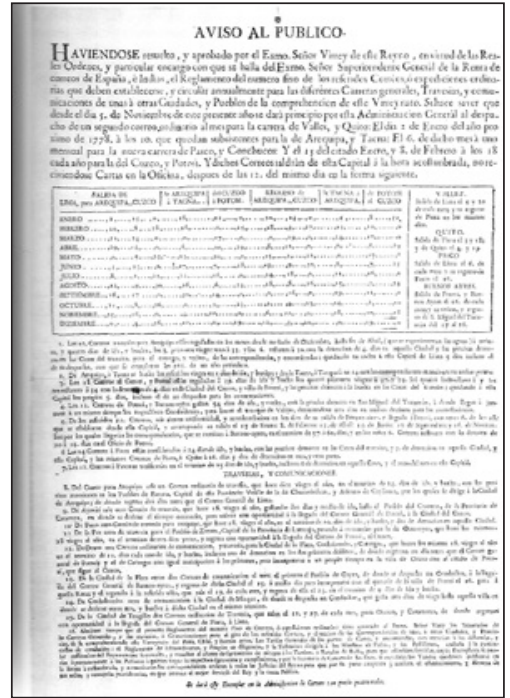

Tabla de salida de correos, finales de 1777. Fuente Sitjá Prats
Un lazarillo de capa y espada: las cuatro PPPP de Alonso Carrió de la Vandera

VIRGINIA GIL AMATE
204). Según Concolorcorvo, la moraleja fue entendida por los porteños del chiste «y a los peruanos no hay necesidad de explicárselo» (p. 204). Los lectores de El lazarillo..., por su parte, podrán conectar este pasaje con otros parecidos que hay a lo largo de relato, así la llamada de atención de Concolorcorvo en el prólogo sobre el trato campechano que el Visitador establece con cualquiera a lo largo de la ruta, su convicción de que el trabajo debe ser remunerado a quien lo realice, conceptuando las artimañas de los indígenas como "propias de gente pobre» (p. 10) no como taras étnicas, frente a las «arrogancias» con las que se conducen «los señores pasajeros, así europeos como americanos» (p. 10). El Visitador de este libro tenía el horizonte mental de su época que observaba las diferencias entre unos grupos humanos y otros en función de su grado de civilización, lo que no tenía era un dique estamental en su mirada ni para los de abajo ni para los de arriba, eso se ve bien en su prosa.

Al Prólogo y al desarrollo del relato añadió Carrió un Apéndice. Constaba, esta última parte de tres apartados dedicados, uno, a señalar las carreras recomendadas en «las provincias de su comisión» (p. 205); otro, a la descripción de Lima; y el tercero, al cierre de la obra. El primero agrupa todas las medidas técnicas tomadas por Carrió en su Visita "para que se dirijan las correspondencias con algún acierto» (p. 205), o, dicho de otro modo, todas las enmiendas realizadas al sistema de Pando y que, para la época en que se difundió El lazarillo..., habían sido aprobadas en su totalidad por los Directores Generales en detrimento de las medidas propuestas por el Administrador Principal. Es decir, a la realidad de lo sucedido en el seno de la administración le agregaba Carrió la difusión pública. Y no es a Concolorcorvo sino al Visitador al que «le pareció muy del caso [...] dar a sus lectores una sucinta idea de las provincias de su comisión» (p. 205). No precisaba Carrió, por tanto, este aparato probatorio de sus méritos y del reconocimiento oficial de estos, lo que sí necesitaba, según parece, es seguir las escaramuzas de su batalla personal con Pando y sus dependiente que, por supuesto, continuaban en 1775 , no en vano el lector al que selectivamente dirige este resumen son «los señores limeños» para que no se fatiguen con «la molestia que les causará el itinerario general» (p. 205).

El segundo apartado comienza con la voluntad de Concolorcorvo de describir Lima y con el Visitador desaconsejando semejante impertinencia porque una pluma de "ganso», como la del amanuense, no puede medirse con la grandeza limeña ni con las descripciones previas de selectos autores, por lo que «sería cosa irrisible que un pigmeo la emprendiese» (p. 211). Pero Concolorcorvo insiste y se pregunta: « $\gtreqless$ es posible que yo he de concluir un itinerario tan circunstanciado sin decir algo de Lima?» (p. 211). Siendo concluyente la respuesta de don Alonso: «Sí, señor Inca, porque a Vm. no le toca ni le tañe esta gran ciudad, porque en ella se da fin a mi comisión» (p. 211). El origen cuzqueño del amanuense da pie, además, a que el Visitador le niegue la posibilidad de «decir algo» sobre Lima por si la querencia natural le hace desmerecer la capital y así, en la ficción conversacional, el Visitador comienza a dar noticias sobre Lima. Ninguna atañe al ramo de correos. De nuevo es la historia de la polémica con Pando la que proporciona sentido a esta parte del Apéndice y al que constituirá el cierre narrativo que los personajes buscan para el relato, aquél que incluye la referencia final a las cuatro PPPP.

El 6 de junio de 1773, llegaba Alonso Carrió a la capital del Virreinato. Comparecía reafirmado en su Comisión puesto que sus medidas habían sido las aprobadas en la Corte y Pando seriamente reconvenido por los Directores Generales en carta de 24 de marzo de 1773 en la que, entre otras cosas, valoraban el buen hacer de Carrió - «Este Comisionado ha dado buena cuenta de todos los ramos de su encargo, el Sor Superintendente ha aprovado quantas disposiciones ha concluido, por el acierto, cordura e inteligencia con que ha procedido» (Sitjá Prats, p. 173)-, amonestaban a Pando - «la lástima es que la irregularidad y la destemplanza no está en el Comisionado, sino en Vm» (Sitjá Prats, p. 174), «no podemos aprobar la conducta de $\mathrm{Vm}$ y antes bien le devemos prevenir disponga el mejor modo de recoger prontamente los ejemplares de la citada su carta circular, escribiendo a todos los Yndividuos y haciendoles las advertencias necesarias para restablecer el buen orden y acertadas disposiciones dadas por el visitador Dn Alonso Carrio» (Sitjá Prats, p. 174)- y le exigían que diera «una completa satisfacción 
a Dn Alonso Carrio» (Sitjá Prats, 2013, p. 174). Las órdenes de ambos confluían en Lima puesto que a uno lo habían nombrado Administrador Principal de la Real Renta de Correo del Virreinato del Perú y a otro Comisionado para el establecimiento de las postas entre Montevideo, Buenos Aires y Lima. Pando había iniciado su viaje en Veracruz donde, en el momento de su nombramiento, era Administrador de la estafeta de Correo Marítimo. A su paso por cada uno de los territorios incluidos en las ordenanzas firmadas por Grimaldi, esto es, de Cartagena a Lima, fue estableciendo las carreras y revisando las diferentes estafetas. Lo mismo hizo Carrió desde el sur y al llegar a la capital solicitó dar fin a su Comisión inspeccionando la Oficina Principal. Por supuesto Pando se negó y el enfrentamiento fue de tal calibre que el Virrey tuvo que convocar una junta para dirimir la cuestión, en ella se incluía a los fiscales de las salas del Crimen y de lo Civil, por tanto en la junta se encontraba presente Antonio Porlier, pero este tribunal falló, el 3 de diciembre de 1773, a favor de Carrió otorgándole el permiso para incluir en su visita la Oficina Principal (Sitjá Prats, p. 185) ${ }^{13}$. En paralelo a las 45 veces en que se reunió dicho Consejo, Pando y Carrió se comunicaban con las autoridades centrales. Pando, por ejemplo, días antes de que el dictamen de la Junta presidida por el Virrey anulara las órdenes que había dado relativas al cierre de los buzones y a la permisión de llevar los conductores de correos cargas para el comercio, obligándolo finalmente a enseñar todas las cuentas de la Oficina Principal al Comisionado, enviaba una carta a los Directores Generales donde señalaba el inconveniente estilo utilizado por Carrió en los numerosos informes que redactó en contra del Reglamento:

Este documento fue para don Alonso un golpe, no menos grave que el que le causó la noticia de mi vida, y al instante le empezó à despreciar, y à impugnar y tratarme de hombre Sin Cerebro, con otros dicterios de mucho improperio [...] No hay uno de los referidos cinco informes en que no se advierta rencor, sátira y desarreglo de voces y conceptos, y en fin son cada uno una general impugnación de mis operaciones y travajo... (20/XI/1773, Sitjá Prats, 2013, p. 184).

Teniendo en cuenta esto, uniéndolo al inicio de la obra en la que Concolorcorvo arrojaba a sus lectores «una V para que cada uno se dé a sí mismo el tratamiento que le correspondiere o el que fuere de su fantasía» (p. 5), podemos seguir la interesante descripción de Lima que hará el Visitador. En ella retrata ponderadamente la ciudad y sus costumbres, refutando tópicos. Utiliza para ello una óptica tan ajena al desdén hacia lo americano que caracterizaba tantas miradas dieciochescas, como a la sorpresa o el exotismo del extranjero, del «bisoño» para utilizar un término del gusto del Visitador. La descripción es cortada por un fragmento final un tanto estrambótico, por supuesto humorístico, que, por eso mismo, por la ruptura que establece con el estilo anteriormente utilizado, se abre a la doble lectura. En ese párrafo final, Concolorcorvo, maravillado con el relato de la riqueza y exquisitez de los ajuares de las casas limeñas, hace explícito su deseo de «ver esa grandeza y palpar esos encajes y plumas» (p. 222). Aspiración graduada por el Visitador de excesivamente elevada, calibrando que quizá no sea «dificultoso que Vm. vea, pero no le permitirán palpar con esas manos de carbonero, de recelo de una mancha o que les deje algún olor a chuño» (p. 222). A partir de ahí el delirio cómico crece en función de la réplica de Concolorcovo y la no menos irónica contestación del Visitador señalando que las camas -siendo este el término o asunto sustituible por cualquier otra cosa porque no es más que el elemento meramente anecdótico para construir sobre él la alegoría que a Carrió le interesa colocar- principales en Lima «las hacen y deshacen señoritas que se mantienen de néctar y ambrosía» (p. 222). Ante la protesta de Concolorcorvo porque lo que él ha visto difiere notablemente de semejante fineza, el Visitador le aclara quienes son esas damas que escriben y viajan de forma etérea:

...estas de que yo hablo son ninfas del Parnaso, presididas del sacro Apolo, que sólo se mantienen, como llevo dicho, de néctar y ambrosía, como los dioses. Sus entretenimientos son elevadas composiciones en prosa y en verso, y cuando alguna quiere pasear todo el orbe en una hora, monta en el Pegaso, que siempre está pronto y paciendo alre[d]hedor del sacro coro (p. 222).

En su día, Carilla había hecho explícita su impresión de que en el ataque de Carrió a sus enemigos, extendido por todo el libro, había una alusión velada a las costumbres y hábitos de estos, y algo de ello debe de haber, si bien
13

La información dada por Real Díaz (1956, p. 397) mueve a confusión porque señala, en e texto de su artículo, la creación de la Junta sin remitir a año alguno $y$, en nota al pie, da como referencia la fecha de resolución del conflicto con el decreto del Virrey de 4 de noviembre de 1774, que es precisamente la fecha en la que se daba el visto bueno a todas las medidas propuestas y realizadas por Carrió. A partir de ese momento empezó a funcionar oficialmente el llamado Plan de Correos de Carrió (Sitjá Prats, p. 153). Tampoco coinciden Real Díaz y Sitjá Prats en los miembros de la Junta, Real Díaz dice estar formada por «dos ministros de aquella Real Audicencia -don Gaspar de Urquizu Ubañes y el conde de Sierra Bella, el Oficial Mayor de la Administración de Lima y el Abogado de la misma» (1956, p. 397). Más concreto es Sitjá «El Consejo estaba formado por: El Virrey (Presidente), Gaspar de Urquizu Ibañez, Antonio Hermenegildo de Querajazu, Manuel Gerena y Vernia, Manuel de Mansilla y Arias de Saavedra, también asistía Gerónimo Manuel de Rueda, Fiscal del Crimen, como Oidor y Antonio Porlier como Fiscal de lo Civil» (Sitjá Prats, p. 185)

Un lazarillo de capa y espada: las cuatro PPPP de Alonso Carrió de la Vandera

VIRGINIA GIL AMATE 
no con la intención escabrosa que parecía intuir Carilla, si tenemos en cuenta los comentarios efectuados por Carrió a Miguel San Martín, en carta fechada el 30 de julio de 1774, aduciendo que «mi edad y modo de pensar se puede conformar jamás con el de estos mozos» (Real Díaz, 1956, p. 393. En realidad, lo que tenemos los lectores ante la vista -sobre todo los que conozcan la diferente forma de viajar hasta llegar a Lima del Comisionado y del Administrador Principal, alquilando casas señoriales Pando, Nava y Plaza (Sitjá Prats, pp. 105-121), alojándose Carrió al raso, en las postas o en las casas de criollos, europeos, indios o mestizos que le brindaban hospitalidad, según cuenta en las páginas de El Lazarillo...; directamente Porcell, reconociendo las rutas Carrió; sin sufrir quebrantos de salud el Comisionado, con agudas dolencias Pando; si además conocen que una de las medidas del Administrador Principal fue ordenar que los conductores lucieran unas pomposas bandas, consideradas por el Comisionado tan engorrosas para el cometido que llevaban adelante que las fue quitando por donde pasó (Sitjá Prats, p. 187) y saben de las críticas que uno y otro hacían del estilo de la escritura del contrario- es un ejercicio de mordacidad rayando en el libelo, más si se observa que el final del segundo Apéndice es el pie de entrada del tercero cuyo objeto es darle broche final al texto y aludir a la suerte crítica que tendrá el mismo.

Comienza con un Concolorcorvo abrumado porque él no entiende nada de Arcadias y Parnasos «ni de antaño y hogaño, allende y acuende, con otros términos, fábulas y figuras» (p. 223) y sospecha que esos señores tan finos, «estos limeños» (y ya aclarará el Visitador, en el curso de ese Apéndice final, que «fuera de Lima se dicen limeños a todos aquéllos que tuvieron alguna residencia en esta capital, ya sean criollos o europeos», p. 224), no dudarán en hacer burla «de un pobre serrano, a que se agrega lo indio» (p. 223). Entre ambos caracterizarán a aquellos seguros receptores, los que ejercerán un juicio negativo, del relato que protagonizan. Don Alonso se mostrará tranquilo porque tiene en cuenta las amplias tragaderas de esos cultos caballeros, mientras Concolorcorvo explicita su desconfianza «porque estos genios son muy clarivoyantes y espíritus muy bellacos, que no perdonan el más leve descuido» (p. 223).
Concolorcorvo quiere terminar la narración dilucidando la preponderancia entre los virreinatos de México y Perú. Es esta otra carrera diferente a las establecidas en el viaje narrado que, sin embargo, confluye en la aparición del mordaz acertijo que ahora se une al «pescado fresco», a los parajes "cálidos y húmedos» y a aquellos productos que, partiendo de «Veracruz», llegan por milagro en buen estado a su destino. A Pando que había recibido su nombramiento el 25 de febrero de 1769 en Veracruz y no había llegado a la capital del Perú hasta el 11 de mayo de 1772, no debió hacerle mucha gracia el chiste:

Los limeños oponen a toda esa grandeza, sus cuatro P.P.P.P., a que pudieran agregar con más fundamento la del pescado fresco, o produ[c]ciones del mar, de que carecen los mexicanos por la mayor distancia, como de dos a ochenta leguas por países cálidos y húmedos, que por casualidad llegan los escabeches de Veracruz a México en estado de poderse comer sin prejuicio de la salud y sin fastidio del paladar (p. 224).

A continuación coloca la «burla chistosa» (p. 224) protagonizada por un «guatemalteco gachupín» y un grupo de "chapetones limeños», en la que hay un «enigma», un «desafío» y una «Junta». El Visitador don Alonso, que es el que ahora dirige el acertijo en contraposición a las otras dos ocasiones en que el juego estaba en boca de Concolorcorvo, tiene cuidado en definir los términos empleados «Para evitar toda equivocación y sentido siniestro» (p. 224) $\mathrm{y}$, como de costumbre, resulta lo contrario de lo que declara: una vez fijado el uso de los vocablos el dardo apuntará certeramente. «Limeño» es la voz utilizada en Perú como sinónimo de lo que en México y en España se denomina «perulero», esto es, todos los que viven o han vivido alguna vez en Lima. «Gachupín», por español residente en América y «chapetón» por recién llegado, parece que no da lugar a confusión puesto que no pasa a definirlos. Bien, el gachupín ha colgado el cartel que desafía a descifrar el uso de las cuatro PPPP, los peruleros, por boca de su «decano» (p. 226), proponen «Pila, Puentes, Pan y Peines» (p. 226) no sin antes reconvenir al gachupín porque por obra de esos comportamientos se «reputa a los chapetones por hombres que solo pensamos en nuestros particulares intereses, sin atender a las particularidades del país» (p. 226). Parece entonces que han ganado esta justa de muchos contra uno: 
Todo el congreso cantó victoria por los peruleros, y faltó poco para que al guatemalteco le echasen de la asamblea por fauto y le condenasen a la talla de refresco sin oirle (pp. 226-227).

Pero el arzobispo, con la venia del presidente, le otorga la palabra al gachupín que cifra la justicia del veredicto en que este depende de «dos hombres sabios e imparciales» (p. 227), por tanto a salvo de la opinión de «los señores limeños» que lo tienen por un «animoso insensato» (p. 227) y bien seguro «de alcanzar una victoria que mis contrarios cantaron por suya» (p. 227). Desde esa confianza, antes de dar su solución rellenando el acertijo con referencias a sujetos, «Pedro, Pardo, Paulino y Perulero» (p. 227), y no a objetos, lanzará una pregunta retórica: «¿No hay, por ventura, otras cuatro P.P.P.P. en el mundo?» (p. 227). Ni que decir tiene que el pulso lo gana el gachupín y la Junta se disuelve, en medio de las risas de sus participantes, reconociendo los chapetones su derrota. Con esa anécdota amable, con ese final feliz que incluye la ácida alusión a las intermitentes PPPP del libro termina «este cansado viaje histórico» (p. 227), presidido y zanjado con el lema latino Canendo et ludendo refero refero vera / Canendo et ludendo retuli vera.

De acuerdo a lo expuesto, es un error de apreciación considerar a El Lazarillo... el producto del informe oficial que las ordenanzas recibidas obligaban a hacer al Comisionado, por más sutilezas y matices que se le quieran agregar a la propuesta ${ }^{14}$. Las apreciaciones de Enrique Rodrigo han sido bien claras al respecto, El Lazarillo... no es un informe oficial y supera las formas el «itinerario» y del «diario» $(1994$, p. 23). Más todavía si las pruebas que deshacían el cariz administrativo del libro se encontraban en los extractos de las cartas enviadas por Carrió a los Directores Generales a lo largo de 1773, donde deslindaba perfectamente los informes oficiales, periódicamente presentados tanto al Virrey como a los Administradores de $\mathrm{Ma}$ drid $^{15}$, del libro que, en ese año, ya anunciaba (Real Díaz, 1956, p. 407). Bien es cierto que en la carta de Carrió a Campomanes fechada en mayo de 1777, alega haber escrito El lazarillo... «de orden de la Direccion General de Correos, y la imprimi a mi costa, à ruego de varios Amigos» (Herrera Navarro, p. 502) pero esa misiva es un importantísimo indicio de que la obra no estuvo tan ajena a problemas como hasta ahora se había pensado. Carrió se dirige en ella a Campomanes al saber, por medio de su altos intermediarios Miguel San Martín Cueto y Julián López de Ayllón, ambos miembros del Consejo de Indias, que el entonces Presidente del Consejo de Castilla, órgano del que emanaban las licencias para la publicación de cualquier libro o escrito por pequeño que fuera ${ }^{16}$, su prohibición o su corrección, había leído la obra y, según le habían dicho a Carrió, la aplaudió (Herrera Navarro, p. 502). Puede entonces pensarse que toda la carta avala el beneplácito con el que contó una obra que llegaba al Consejo ya impresa, con pie de imprenta falso y sin que figurara el auténtico nombre de su autor, siendo estos procedimientos que contravenían las leyes y cédulas reales sobre la impresión de libros que, lejos de haberse suavizado en la época de Carlos III, se habían incrementado en la idea de controlar la fiabilidad y la calidad de lo publicado (Lopez, 1995; Caro López, 2003; Caro López y Bragado Lorenzo, 2004). Sin embargo, la carta es más bien un ejercicio de autodefensa frente a críticas que, al más alto nivel, se le estaban haciendo a Carrió y a su obra.

Uno de los juicios atañe al contenido mordaz del relato, considerando que «el Librito debía ser quemado en Plaza pública por no contener mas que una serie de Satiras contra todo el Reino" (Herrera Navarro, 2009, p. 503); otro, al «mal estilo» con el que estaba escrito, que al igual que el anterior, podía condenar a una obra al limbo del silencio por no considerar apto al autor en relación con la materia o por no dar que hablar sobre el nivel cultural de la nación a las plumas extranjeras, más si los asuntos tratados aludían a Indias, en general, y a la mala gestión administrativa de un ramo (o de varios, porque de todo hablan don Alonso y Concolorcorvo) tocantes a materias de Estado, en concreto.

La relativa a la sátira no era ninguna broma (Serrano Sanz, 1906) al constarle a Carrió que había sido expuesta, en carta enviada a Lima, por «Cierto Ministro, que viste la Ropa semejante a la de su Iltma» (Herrera Navarro, 2009 , p. 503), dando la suficiente información sobre el sujeto -así sus estudios de Derecho Civil y Canónico, haber tenido «alguna práctica de Curia», su condición de Fiscal, la alusión a pleitos en territorios del Tucumán y el hecho de que «Este Ministro hizo el mismo viage que yo» (Herrera Navarro, 2009, 503),
14

Sea que El Lazarillo «básicamente está formado por los informes del viaje objeto de su comisión que debía rendir a los Adminis tradores Generales de Madrid, según las instrucciones recibidas pero dado el carácter tan poco convencional de esos informes, y todo lo que le añadió de su parte, se puede deducir que el propio Carrió se adelantó a los posibles reparos que le podían poner sus superiores, ya que era consciente de que el resultado escrito de su viaje excedía en mucho al encargo que se le había hecho y por eso la imprimió a su costa» (Herrera Navarro, p. 508); sea que «Los funcionarios de los correos virreinales son los destinatarios del informe burocrático que Carrió de la Vandera es encargado de entregar al concluir su visita de inspección y finalmente nosotros leemos El lazarillo de ciegos caminantes, resultado final de ese informe metamorfoseado en discurso narrativo» (Stolley, p. 129).

15

El 8 de agosto de 1772 presentó al virrey Amat una Representación sobre el estado de los correos; el 3 de septiembre de 1773, elevaba otra; el 1 de junio de 1774 enviaba un «Manual de Correos y maestros de postas, con el itinerario de las leguas, que cada una distan entre sí en las tres rutas generales de este virreynato del Perú»; y el 17 de agosto de 1776 dirigía al nuevo virrey un Informe sobre el estado de los correos. A todos ellos se sumaban el Diario Náutico y las informaciones sobre rutas, postas, costes, nombramientos, etc que despachó por cartas durante su viaje.

16

Así estaba establecido desde el Reglamento dado por Juan Curiel como Juez de Imprentas de 22 de noviembre de 1752. Durante el reinado de Carlos III, y a partir de 1762, con Campomanes como Presidente del Consejo de Castilla, se rebajará el rigor de la legislación inspirada por Curiel pero no por ello desparecerá el control que obligaba al paso por la censura previa (Novísima reco pilación de las leyes de España 1805 y Reyes Gómez, 2000).

Un lazarillo de capa y espada: las cuatro PPPP de Alonso Carrió de la Vandera

VIRGINIA GIL AMATE 
17

Para contrastar los datos biográficos del Marqués de Bajamar, Guimerá Pedraza (1981)

18

Carrió recoge el dicho popular extendido entre la población hispánica de América: «En algunas ciudades a las Rales Cé[d] ulas llaman los españoles hostias sin consagrar» (Lorente Medina, p. 245); cuyo uso llegaba hasta México puesto que antes de finalizar la centuria, Hipólito Villarroel en Enfermedades políticas que padece la capital de esta Nueva España..., empleaba con apenas diferencias el giro para referirse a la percepción de la población sobre el código legislativo que los regía: "porque las expresadas Reales Cédulas, órdenes y demás providencias son (como vulgarmente se dice) hostias por consagrar que fácilmente se interpretan para que se dificulte su ejecución» (c. 17851786 ; 1979 , p. 110)

19

«Mui SSres mios: En este Navío de Comercio nombrado el Aquile, incluyo a Vss el duplicado de el n 5 por ser el mas interesante a la Renta. Asimismo dirijo a Vss otro paquete con seis ejemplares de mi viaje de Tierra, que aunque es difuso, puede aprovechar a algunos Dependientes de la Renta, para que se imponga en el distrito de su Comision. En los demas asuntos como tengo avis, no haremos novedad, hasto que llegue el nuevo Sr. Virrey, a quien presentaré un Ynforme de los tres estados de este Ramo, desde la incorporacion a la $\mathrm{Co}$ rona» (Sitjá Prats, p. 178).
Un lazarillo de capa y espada: las cuatro PPPP de Alonso Carrió de la Vandera

VIRGINIA GIL AMATE pero podría haberlo realizado mejor si hubiera tenido a mano el «Diario» de Carrió- como para identificar -aquí sí, en 1777, y no en $E l$ Lazarillo, y su época de redacción entre 1773 y 1775 , cuando las primeras y últimas terminales de ataque del Comisionado no estaban en la Audiencia de Lima sino en la Administración Principal de Correos del virreinato-, a Antonio Porlier y Sopranis ${ }^{17}$, que, para esas fechas, ya estaba incorporado a su puesto de Fiscal del Consejo de Indias, órgano al que se destinaban, desde el Consejo de Castilla, los manuscritos relativos a América para estimar, o no, la viabilidad de su publicación, siempre y cuando el autor hubiera cumplido con la ley expresa, que no es el caso de El Lazarillo...

Con el asombroso desparpajo del funcionario que cree que tanto su persona como su labor y su esfuerzo ha sido y sigue siendo bien considerado en la Corte y que eso es lo único que cuenta para ser respaldado por las autoridades, Carrió le apunta a Campomanes:

Si con todo lo dho, se mantubiere el señor Togado, en que la Obra es Satirica, porque no contiene mas que desnudas verdades, acuse tambien a todos los A.A. de la Historia Sagrada, y Profana en todos aquellos hechos que descubren los vicios, y defectos de los maiores hombres del Mundo; y sobre todo, viene ese Caballero á tratar tácitamente de Candidos, y simples á todos los Sabios de Lima, porque no conocieron la Sátira (Herrera Navarro, p. 504)

El autor apoyaba su defensa en la verdad de lo que relataba que alejaban su texto, según su criterio, del libelo mordaz aunque para ello tuviera que negar ante el Presidente del Consejo de Castilla la utilización del registro satírico. Si bien sus mismas palabras ponían de manifiesto la pluralidad de lecturas e interpretaciones que podía tener El Lazarillo..., la de aquellos que lo celebraban por considerarlo un libro útil, práctico; la de aquellos que advertían, obviamente, el contenido satírico; y la de aquellos que, no sin motivo, se sentían personalmente molestos:

...no me ha pasado por la imaginacion el que esta obra fuese aplaudida, y solo me contentaré con que se estime por util, y casi necesaria en estos Reynos, adonde la Celebraron todos, a excepción de algunos Embidiosos (Herrera Navarro, p. 504).

Es decir, para sus coetáneos, incluido el autor, había una doble posibilidad de lectura de un libro construido bajo el ameno arma- zón del diálogo entre dos personajes que, a lo largo del tiempo, se ha multiplicado debido a lo que Enrique Pupo-Walker llamó el «repertorio sorpresivamente amplio de códigos literarios e historiográficos» (1982, p. 188) utilizados por Carrió en su narración. Claro que ninguno de esos registros, los de antes y los de ahora, evitaban el incómodo trance marcado para los escritos que quisieran verse impresos en el siglo XVIIII. Esto es, enviar la obra al Consejo de Castilla, esperar a que este las distribuyera entre los organismos competentes al asunto tratado, seguir esperando con paciencia a que fuera leído por el censor designado, confiar en que a criterio de este la obra fuera digna de las prensas, finalmente, si el veredicto era favorable y el autor se encontraba en América, aguardar a que el barco con la licencia de impresión salvara los variados peligros de la travesía. Se ve que no llegaba a tanto la perseverancia de Carrió o que en Indias se habían visto abocados de tantas órdenes, contraórdenes, demoras que obligaban a actuar por libre o interpretaciones personalistas de las leyes que podían perjudicar muy mucho a los vasallos, a considerar las Reales Cédulas, según palabras de Carrió en su Plan de gobierno para el Perú, «hostias sin consagrar» ${ }^{18}$. Es sabido que en el caso de El Lazarillo... este ir por libre llegó al punto de mandar a los Directores Generales, en abril de 1776, «12 ejemplares de mis Ytinerarios desde Montevideo a esta Capital», indicando que seis de ellos ya tenían dueño, «Los SSres Sn Martín, Otamendi, y Ayllon» y el resto podían repartirlos «a quienes les pareciere» (Real Díaz, p. 409). Para reincidir pocas semanas después, en mayo de 1776, enviando otros seis ejemplares acompañados de una carta en la que distinguía el informe oficial que cursaría al nuevo virrey y las advertencias técnicas dadas por carta a los propios Directores, del libro que enviaba ${ }^{19}$. Van, por tanto, 18 libros de un total de 500 impresos sin licencia, de los que cien, por voluntad declarada del autor, iban a ser (o habían sido, puesto que Carrió no conocía la galbana, ni la parsimonia, ni mucho menos las componendas que esconde la prudencia) distribuidos entre sus «Amigos» y los «Administradores Mayores de la Renta, desde Montevideo a Cartagena con sus Travesías» (Real Díaz, 1956, p. 410), el resto estaba destinado a la venta según una tasación que no necesitaba intervención 
alguna de las autoridades designadas para tal fin, ya se encargaba Carrió de hacerla para ver si se resarcía de los «más de 400 pesos de mi propio caudal» (Real Díaz, 1956, p. 410) que había empleado en la empresa. Por si fuera poco anuncia, en carta de finales de mayo de 1776, la remisión, en la próxima «Fragatita de el Rey, nombrada la Paz» (Sitjá Prats, p. 178) de otros 12 ejemplares de los que pueden disponer «a su arbitrio» (Sitjá Prats, p. 178) los Directores Generales, confirmando el envío el 31 de mayo de 1776. Van 30 libros dirigidos a las autoridades centrales de la Real Renta de Correos y a varios miembros del Consejo de Indias. Convengamos que, cuanto menos, es un caso curioso en la historia de la censura de libros americanos durante el siglo XVIII ${ }^{20}$, no dudo que se podrá contestar, espontánea (y erróneamente), levantando el banderín de la absoluta comunión de ideas "colonialistas», entre Carrió y el poder imperante hasta convertir El lazarillo..., contra toda evidencia, en una «singular proclama antiamericana» (Prieto, 2006, p. 24). Pero como ese no es un camino adecuado para entender este enredo, volvamos a preguntarnos si el libro le acarreó inconvenientes a Alonso Carrió de la Vandera que para nada disimuló su autoría, ni puso a Concolorcorvo como escudo ante sus enemigos locales, ni utilizó esa estrategia editorial por estar inseguro de los logros alcanzados en su gestión y en su escritura. Más bien situar a Concolorcorvo al frente de la obra redoblaba el amargo efecto que causaría la crítica inmersa en esas páginas entre sus colegas de la Oficina Principal. Era una mofa más, por supuesto no construida para denigra o redoblar el sometimiento de lo indígena porque Carrió estaba en una guerra que nada tenía que ver con la cruzada de parte de la crítica actual. Es más, si el amanuense esperaba obtener a través del libro «la plaza de perrero de la catedral del Cuzco» (p. 13), Carrió mantenía la tesitura indicándole a Campomanes que no se le había pasado por la imaginación solicitar «a V.S. el que me de los honores de Portero de la Academia» (Herrera Navarro, 2009 p. 504) ya que tantas veces se le había acusado de pretender el puesto de Pando o el de Nava. Nada velaba el pie de imprenta, en él figuraba como autor el secretario temporal del Comisionado, la ciudad de nacimiento de Carrió era el supuesto lugar de impresión, el momento cumbre de la trifulca con Pando pasaba por ser el año de la impresión y, para redondear el bromazo, todo se había impreso en «la Rovada» que ni siquiera se molestaba en dar fe de erratas por indicadas que estuvieran en la normativa vigente.

Como cualquier interesado en la obra de Carrió puede saber como le ha ido en nuestra época, veamos cómo le fue en la suya. Seis meses después del primer envío de ejemplares, el 26 de octubre de 1776, Carrió recibía carta de Antonio de la Quadra, Juez Director General de Correos y Postas de España y de las Indias, en ella, hacía acuse de recibo de los primeros volúmenes enviados, sin poder emitir juicio alguno sobre ellos "por no haver tenido tiempo aun de reconocerle con la debida atención» (Sitjá Prats, 2013, p. 178). En principio, la predisposición de Quadra no era negativa - «parece una obra curiosa y que será útil e instructiva al Público, y aun a esta Renta en la parte que le toca» (Sitjá, Prats, 2013, p. 178)-, aunque con cierta frialdad le indica que es otra cosa lo que está esperando la Real Renta de Correos -«Lo que a esta mas principalmente combiene es el tratado que insinua comprehensivo de la Renta de Piura a Lima y de aquella Capital a Arequipa, con una puntual demostracion de las distancias, terminos en que giran los Correos, o pueden girar; establecimiento de Postas, estafetas y lo demas concerniente al mejor servicio de las correspondencias en utilidad al Publico, y de la misma Renta» (Sitjá Prats, p. 178)-. En el colmo de la inopia o de la falta de escrúpulos ante lo que estaba ocurriendo en el virreinato, le indica, además, que para realizar tal tratado se ponga de acuerdo con Pando puesto que este había formado «un cuadernito comprehensivo de su tránsito por el nuevo Reyno de Granada hasta esa Capital» (Sitjá Prats, 2013, p. 178). Una vez redactado dicho informe ni de lejos se le podía pasar por la imaginación publicarlo, sino remitirlo «aquí con tanto manuscrito para tratar de su vista lo que conbenga sobre darlo o no a la estampa» (Sitjá Prats, 2013, p. 178).

Por su parte, Carrió, en la carta enviada a Campomanes en mayo de 1777, parecía estar defendiéndose de más críticas que las alusivas a la sátira y el mal estilo, entre ellas que hubiera campado por sus fueros a la hora de imprimirlo:

Dichos SS.es S. ${ }^{\mathrm{n}}$ Martín, y Ayllon, dicen, que si hubiera embiado el quaderno para que se imprimiera allá, se omitirian algunas cosas por impertinentes, sin señalar quales son (Herrera Navarro, 2009, p. 502).
20

La historia de la censura en Indias se ha hecho a través del estudio del código legislativo (Toribio Medina, 1958) o incidiendo en la reiteración de leyes burladas y, por tanto, en la circulación de libros e impresos que no se ajustaban a las prohibicione (Torres Revello, 1940; Leonard, 1949). Esta última vía, más ajustada con la realidad cultural de Indias, se abrió al estudio tanto de los textos impresos como de los manuscritos (Zavala, 1978) y continúa en nuestros días.
Un lazarillo de capa y espada: las
cuatro PPPP de Alonso Carrió de la Vandera

VIRGINIA GIL AMATE 
La suerte de Carrió estaba echada, no sólo porque Grimaldi, que en tan alta estima lo tenía, hubiera sido sustituido en la Secretaría de Estado por Floridablanca. El hecho de que ese mismo año pasara a ser Contador-Interventor de la Administración Principal de Lima, por promoción al ser nombrado José Álvarez de Nava Administrador de La Paz, no debe confundirnos de los márgenes de tiempo que mediaban entre la publicación de El Lazarillo..., su envío a España y el negativo efecto que causó en algunas autoridades comprobar que en Indias, territorios que pretendían tener bien controlados, gente como Carrió, miembros de la nueva República de las Letras por su propio talento y por que consideraban que tenían algo importante que decir, iban, según corría el espíritu de época, pensando que podían publicar lo que escribían. Afortunadamente el libro no fue quemado en plaza pública, bastó que Carrió diera ese mismo año otro paso en falso, con el intento de impresión, otra vez sin licencia, de un Manifiesto. Esta vez pudo adelantarse Pando y cursar la denuncia pertinente, y el peso de la ley distante cayó sobre Carrió, por más que el fiscal de la Audiencia de Lima, Serafín Veyan, determinara, el 24 de noviembre de 1777, que el escrito no atentaba contra el honor de nadie y su contenido era beneficioso para el mejor manejo de los Correos peruanos:

Sobre la naturaleza del Papel o Manifiesto, no puedo menos de hacer presente, que haviendolo reconocido con la devida atención, està tan lejos de reputarlo como libelo infamatorio que antes lo considero como util e importante al servicio del Rey y como producción legitima del celo que manifiesta el Autor (Sitjá Prats, 2013, p. 193).

Finalmente las PPPP veladas salvo para los que se sentían identificados o para los que podían identificarlos ganaban la partida, Carrió era pasado a la jubilación forzosa con deshonor y con el desconcierto de que los mismos Directores Generales que durante años aprobaron su gestión y sus medidas le espetaran, el 25 abril de 1778, cuando todavía hacía intentos para rehabilitar su buen nombre, que de ninguna manera sacarían «la cara por $\mathrm{Vm}$, quando conocemos el atentado en que ha incurrido» (Sitjá Prats, 2013, p. 195). El antiguo Comisionado les contestaba con amargura, «Si los travajos, disgustos y perdidas que he experimentado en cerca de ocho años que sirvo a S.M. empleado en la Renta de Correos, no hubieran fortalecido mi espíritu, tengo por cierto, que en el contexto de la carta de Vss. del 25 de abril del presente año, me huviera quitado la vida» (Sitjá Prats, 2013, p. 195). Les indicaba, además, que la imputación que le hacían, esto es, revelar secretos de la Renta de Correos, «es un crimen nuevo, de que no se hizo aquí cargo, en medio del deseo, que tenían mis contrarios de abultar mis delitos» (Sitjá Prats, 2013, p. 195).

José Joaquín Real Díaz en un estudio que abría muchas y muy sugerentes vías de investigación de El lazarillo..., trazaba, paradójicamente, una extraña semblanza de Alonso Carrió de la Vandera que no se corresponde con su labor, ni con sus actuaciones, ni con las ideas que sus personajes dieron en el libro. Calificaba en ella a Carrió como un individuo «demasiado apegado a la letra de la ley», marcado por «una sumisión total a las órdenes de sus superiores» (Real Díaz, 1956, p. 392). Es esta una imagen si no repetida sí presente en el sustrato de muchos trabajos posteriores. No fue esa, sin embargo, la idea extraída, a través del análisis de la obra, por Enrique PupoWalker, que encontraba en Carrió, «tras su reafirmada condición peninsular», un punto de vista, «un plano vivencial -el más significativo de toda su vida-, que está cifrado plenamente en la cultura del criollo» (1982, p. 179). Efectivamente, eso fue, a mi criterio, Carrió, un español europeo que junto a los criollos, a los españoles americanos, formaban el segmento hispánico de la sociedad virreinal. Como tantos de ellos, sintiéndose un leal vasallo que había cumplido con su cometido, bien lejos de los vaivenes de la Corte, experimentaba la arbitrariedad de un sistema que tanto podía consentir la circulación de una extensa obra que contravenía toda la normativa vigente durante el último cuarto del siglo XVIII sobre la impresión de libros, como caer sobre un Manifiesto considerado útil en el virreinato o, en fin, ir aprobando durante años las medidas técnicas propuestas por un Comisionado, en detrimento de las directrices dadas por el Administrador Principal, pero mantener a este en su puesto, alimentando una disputa, que por lo visto no les quitaba el sueño a las autoridades centrales, en un sector de primera necesidad para la población de Indias, claramente lo había apuntado Concolorcorvo: en cada posta, en cada oficina de correos, "no solamente había intereses del rey, sino del público» (p. 127). 


\section{Bibliografía}

Almanza Gálvez, Carla Mariela (2005), Parodía satírica del relato de viajes y discurso reformista en El lazarillo de ciegos caminantes de Alonso Carrió de la Vandera, Lima, Universidad Católica del Perú, Tesis PUCP [en línea:

http://tesis.pucp.edu.pe/repositorio/bitstream/handle/123456789/835/ALMANZA_GALVEZ_CARLA_PARODIA_SATIRICA.pdf?sequence $=1]$ )

Bataillon, Marcel (1960), «Introducción a Concolorcorvo y a su Itinerario de Buenos Aires a Lima», Cuadernos Americanos, vol. CXI, n. 4, julio-agosto, pp. 197-216.

Bose, Walter B. L. (1938), «Alonso Carrió de la Vandera, visitador de la Real Renta de Correos en el Río de la Plata, (1771-72)», Revista de Correos y Telégrafos, Buenos Aires, ns. 15-16.

Bose, Walter B. L. (1941), «El lazarillo de ciegos caminantes y su problema histórico", Labor de los Centros de Estudio, Universidad Nacional de La Plata, Sección II, tomo XXIV, n. 3, pp. 219-287.

Carilla, Emilio (1973), introd. a Concolorcorvo, El lazarillo de ciegos caminantes, Barcelona, Labor.

Caro López, Ceferino (2003), «Los libros que nunca fueron. El control del Consejo de Castilla sobre la imprenta en el siglo XVIII», Hispania. Revista Española de Historia, vol. 63, n. 213, pp. 161-198.

Caro López, Ceferino y Bragado Lorenzo, Javier (2004), «La censura gubernativa en el siglo XVIII», Hispania. Revista Española de Historia, vol. 64/2, n. 217, pp. 571-600.

Fernández Insuela, Antonio (1990), «Un dato sobre un enigma del Lazarillo de ciegos caminantes», Bulletin Hispanique, t. 92, n. 2, julio-diciembre, pp. 847-856.

Guimerá Pedraza, Marcos (1981), «Don Antonio Porlier, Marqués de Bajamar (17221813)», Anuario de Estudios Atlánticos, n. 27, pp. 113-207.

Herrera Navarro, Jerónimo (2009), «Alonso Carrió de la Vandera, autor del «Lazarillo de ciegos caminantes»: prueba documental», Cuadernos para la Investigación de la Literatura Hispánica, n. 29, pp. 499-511.

Hill, Ruth, Hierarchy (2005), Commerce, and Frand in Bourbon Spanish America: A Postal Inspector's Exposé, Nashville, Vanderbilt University Press.
Klien-Samanez, Mónica (2002) «El lazarillo, Fray Calixto y las cuatro P», Revista de Crítica Literaria Latinoamericana. Año XXVIII, n. 55, $1^{\text {er }}$ Semestre 2002, pp. 2135.

Lopez, François (1995), «El libro y su mundo», Joaquín Alvárez Barrientos, François López e Inmaculada Urzaínqui, La República de las Letras en la España del siglo XVIII, Madrid, CSIC, pp. 63-123.

Lorente Medina, Antonio (1985), intro. a Alonso Carrió de la Vandera, El lazarillo de ciegos caminantes, ed., Caracas, Biblioteca Ayacucho.

Medina, José Toribio (1958), Historia de la imprenta en los antiguos dominios españoles de América y Oceania, 2 vols., Santiago de Chile, Fondo Histórico y Bibliográfico José Toribio Medina.

Novísima recopilación de las leyes de España (1805), tomo IV, Libros VIII-IX.

Pupo-Walker, Enrique (1982), «En el azar de los caminos virreinales: relectura de $\ll \mathrm{El}$ lazarillo de ciegos caminantes»», en La vocación literaria del pensamiento bistórico en América, Madrid, Gredos, pp. 156-190.

Prieto, Martín (2006), Breve bistoria de la literatura argentina, Buenos Aires, Taurus.

Real Díaz, José Joaquín (1956), «Don Alonso Carrió de la Vandera, autor del Lazarillo de ciegos caminantes", Anuario de Estudios Americanos, vol. XIII, pp. 387-416.

Real Díaz, José Joaquín (1959), prólogo a Concolorcorvo, El lazarillo de ciegos caminantes, BAE, n. 122, Madrid, Atlas.

Reyes Gómez, Fermín de los (2000), El libro en España y América. Legislación y censura (siglos $X V-X V I I I)$, vol. I, Madrid, Arco/Libros.

Rodrigo, Enrique (1994), "Un viaje algo circunstanciado': El destinatario de El lazarillo de ciegos caminantes», Juan Villegas, coord., Encuentros y desencuentros de culturas: siglos XIX y XX. Actas de XI Congreso de la Asociación Internacional de Hispanistas (1992), Irvine, AIH, vol. 4, pp. 21-27.

Serrano Sanz, Manuel (1905), «El consejo de Castilla y la censura de libros en el siglo XVIII», Revista de Archivos, Bibliotecas y Museos, n. 15, pp. 28-46.

Sitjá Prats, Jesús (2013), El correo colonial en el virreinato del Perú. Siglos XVIII y XIX, Real Academia Hispánica de Filatelia, Discursos Académicos XXVIII.
Un lazarillo de capa y espada: las cuatro PPPP de Alonso Carrió de la Vandera

VIRGINIA GIL AMATE 
Stolley, Karen (1992), El lazarillo de ciegos caminantes: un itinerario crítico, Hanover, Ediciones del Norte.

Torre Revello, José (1940), El libro, la imprenta y el periodismo en América durante la dominación española, Buenos Aires, Peuser.

Villarroel, Hipólito (c. 1785-1786; 1979), Enfermedades políticas que padece la capital de esta Nueva España..., intro. Genaro Estrada, estudio prel. Aurora Arnaiz Amigo, México, Miguel Angel Porrúa.
Zanetti, Susana (2002), «La trama de lectura y escritura en El lazarillo de ciegos caminantes de Alonso Carrió de la Vandera», en La dorada garra de la lectura. Lectoras y lectores de novela en América Latina, Rosario, Beatriz Viterbo, pp. 19-59.

Zavala, Iris (1978), Clandestinidad y libertinaje erudito en los albores del siglo XVIII, Barcelona, Ariel.

Fecha de recepción: 26/06/2013

Fecha de aceptación: 29/07/2013 